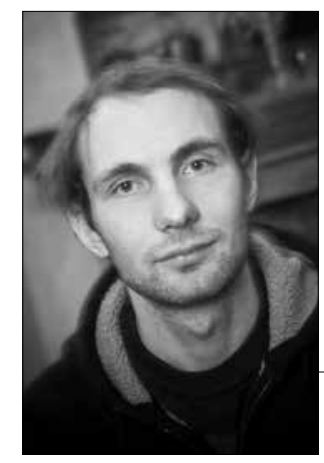

Prano Dovydaičio premijai

https://doi.org/10.24101/logos.2019.49

Gauta 20190312

NERIJUS STASIULIS

Vilniaus Gedimino technikos universitetas, Lietuva

Vilnius Gediminas Technical University, Lithuania

\title{
L. WITTGENSTEINO PSICHOLOGIJOS IR RELIGIJOS FILOSOFIJA
}

\section{Wittgenstein's Philosophy of Psychology and Religion}

\begin{abstract}
SUMMARY
This is the third and last of a series of articles on Wittgenstein's philosophy of psychology. It continues the discussion of the previous topics: the critique of scientific psychology; of seeing aspects of experiencing meaning directly. The article does this now with respect to their practical or "cultural" significance. Wittgenstein's remarks on psychology are placed in the context of his thought on religiosity and culture. The major ends of current philosophical thought are also interpreted within the context of personal and cultural "meaning-blindness". The article suggests that a direct experience of the logic of Sprachspiele indicates also a practical change both in the broader cultural context and the narrower personal one.
\end{abstract}

\section{SANTRAUKA}

Tai trečiasis ir paskutinis straipsnių ciklo apie Wittgensteino psichologijos filosofiją straipsnis. Čia tęsiamos ankstesniuose straipsniuose aptariamos mokslinès psichologijos kritikos, aspekto pastebẻjimo, tiesioginès reikšmės pagavos temos, šikart kreipiant dėmesį i jų praktinę ar "kultūrinę" reikšmę. Wittgensteino pastabos apie psichologiją perkeliamos i jo mąstymo apie religingumą ir kultūrą kontekstą. Asmeninio bei kultūrinio „aklumo reikšmei“ kontekste interpretuojami ir pagrindiniai šiuolaikinio filosofinio mąstymo tikslai. Teigiama, jog tiesioginis save rodančios Sprachspiele logikos patyrimas nurodo ir praktini pokyti tiek bendresniame kultūriniame, tiek siauresniame asmeniniame kontekste.

\section{ASPEKTO MATYMAS IR RELIGINGUMAS}

\section{Žmogus, kuris neturètų minties žaibo reikšmei“" (Bedeutungsblind) (Wittgen-} greičio, anot Wittgensteino, būtų ",aklas stein 1984: I §344). Jis negalètų suprasti 
reikšmès, bet - geriausiu atveju - vien ją numanyti (kaip ir aspekto pastebejjimo atveju). Būtent gebejjimas patirti žodžio reikšmę negyvus ženklus (žodžius kaip ženklus) igalina turèti reikšmę, juos atgaivina. Wittgensteino žodžiais tariant, reikšmės patirtis igalina pamatyti žodžio „veidą" (Gesicht), "charakterį" (Charakter), „jauseną“ (Gefühl), "sielą“ (Seele) (pvz., žr.: Wittgenstein 1984: §243, §322) bei, viena vertus, teisingai juos vartoti konkrečioje situacijoje, kita vertus, suvokti konkrečios kalbinės išraiškos reikšmès niuansus konkrečiame kontekste. Siejant su kalbos išraiškų reikšmės supratimu, Wittgensteino vèlyvojoje filosofijoje ,analogijai su muzika ir muzikos supratimu skirtas ryškus aiškinamasis vaidmuo" (Bar-Elli 2006: 246): panašiai išgirstame arba išgrojame niuansus muzikiniame kūrinyje (tas pat Wittgensteino filosofijos kontekste pasakytina apie visą meną). Tą pati sąryši nurodo Wittgensteinas ir šiais žodžiais: „Kartais sakini galima suprasti tik tada, kai jis skaitomas tinkamu tempu. Visus mano sakinius reikia skaityti lètai“ (Wittgenstein 1980: 57). Nors visiškas aklumas reikšmei turbūt nepasitaiko, t. y. nèra tokio žmogaus, kuris tiesiog visiškai nesugebètų išmokti ir suvokti kalbos, tačiau, kaip nurodo Bar-Elli, sugebejjimas patirti reikšmę „,taip pat yra sąlyga vartoti [ir suprasti] žodžius ,„šalutine prasme“" kuri savaime yra itin reikšminga“ (Bar-Elli 2006: 224). Žodžio „šalutinè prasmè" yra gimininga aspektų pastebejjimui paveiksle ar muzikos kūrinyje: nors turbūt nèra žmogaus, kuris nesugebėtú suvokti, jog štai čia yra paveikslas ar muzikos kūrinys (o ne šiaip spalvų ar garsų visuma), vis dèlto visiškai įmanoma juose nepastebèti „šio to daugiau“. Paprasta suvokti, jog štai čia yra ritualas, bet visiškai įmanoma „nepastebèti“ jo prasmès, jeigu ignoruojama tai, kad ji „rodo save“.

Psichologijos ar antropologijos (Stasiulis 2017) žmogus yra "aklas reikšmei“. Toks žmogus (neturintis žodžio reikšmės patirties), „nuolat interpretuoja ir nesugeba intencionaliai mąstyti“ (Bar-Elli 2006: 242). Bar-Elli aprašo tokį žmogų kaip tam tikrą zombį: toks žmogus „,elgtųsi ir reaguotų i žodžius labai panašiai kaip mes, ir vis dèlto tik „kalkuliuotu“ juos, nieko jais nereikšdamas" (Bar-Elli: 241). Wittgensteinas žmones, neturinčius ,,žaibiško minties greičio“, ivvardija kaip „automatus" (Wittgenstein 1984: I §197-198) arba „robotus“ (Witgenstein 1984: I §324).

Baudrillard'as yra pasakęs, kad Disneilendas egzistuoja tik tam, kad nuslèptú, jog visa Amerika yra disneilendas. Panašiai galima pasakyti, kad ginčas dèl dirbtinio intelekto sukūrimo galimybès tik slepia tai, jog mes jau funkcionuojame kaip dirbtinis intelektas. Wittgensteinui žmogaus samprata rūpejjo dèl to, kad jos raiška buvo „kultūra“, žmonių gyvenimo būdas. Žmogaus samprata, kurioje nèra vietos „,sielai“ ar „,žaibiškam minties greičiui“", (at)vedè prie civilizacijos, kurioje žmonių gyvenimo būdas paveiktas nesugebejjimo pastebèti svarbių save rodančiu aspektų. Civilizacijoje, kurioje mokslingi psichologai pakeičia Dostojevskio senolio Zosimos tipo sielos gydytojus, žmonès ima panašèti i minimus robotus.

Wittgensteino pastabos apie sielą, meną ir žodžio reikšmę susijusios ir su 
religija: „Religija moko, jog kūnui suirus siela gali išlikti. Ar suprantu tai, ką ji moko? - Žinoma, suprantu - galiu ìsivaizduoti daugybę su tuo susijusių dalyku. Apie juos ir paveikslu nutapyta. Kodèl toks paveikslas turètų tik netobulai perteikti išsakytą mintį? Kodèl jis neturètu atlikti tokio pat vaidmens, kaip ir išsakomi žodžiai? Kaip tik tas vaidmuo čia ir yra svarbus" (Vitgenšteinas 1995: 334). Churchillis (1998: 158) nurodo, jog būtent Wittgensteino vaizdo (picture, Bild) idejja susieja jo aptartų fenomenu - „linijiniu piešinių, kelrodžiǔ, paveikslų, žodžių reikšmių pagavą" (Churchill 1998: 158). Wittgensteinas kalba apie religinius simbolius kaip apie vaizdus, kurie reiškia nuostatą (Einstellung, attitude) (žr.: Churchill 1998: 162) pasaulio atžvilgiu, ir pabrèžia, jog nuostata nèra nuomonè (=interpretacija): „Argi tikejjimas Dievu nèra nuostata?" (Wittgenstein, cit. pgl. Churchill: 163). Vadinasi, tikèjimas Dievu kyla būtent iš savirodos, o ne mokslinio ar kvazimokslinio aiškinimo.

Būtent žodi „Einstellung“ Wittgensteinas vartoja kalbėdamas apie aspekto matymą: „Bet ar aš taip pat matau vaiz$d q$ šiuo aspektu tik tol, kol jo atžvilgiu turiu šią nuostatą? - Galima taip pasakyti“ (Wittgenstein 1984a: §670, kursyvas N. S.). Taip pat - kalbėdamas apie požiūrị i sielą: "Mano nuostata jo atžvilgiu yra nuostata sielos atžvilgiu" (Vitgenšteinas 1995: 334; Wittgenstein 1958: 178, kursyvai - N. S.). Taip pat - apie požiūrị i filosofiniu problemų sprendimą: „Juk atpažinti filosofijos problemą kaip loginę yra pažanga. Su ja ateina tinkama nuostata" (Wittgenstein 1984: §256, kursyvas $-N$. S.).
Atpažinti religinius simbolius kaip vaizdus, kurie "rodo save“ - tai pastebèti aspektą. $\mathrm{O}$,ju pati prigimtis kaip vaizdu, [Wittgensteino požiūriu,] yra ju vartojime" (Churchill 1998: 160), t. y. pastebèti aspektą - tai "gebèti naudotis tuo, kas vaizduojama, žinoti, kaip pritaikyti savo turimą dalyko, laikomo tuo ir tuo, vaizdą - būti įvaldžius tą techniką" (Churchill 1998: 160). Kitaip sakant aspekto pokytis pasireiškia kitokiu veikimo būdu: „Vidinis procesas“ reikalauja išorinių kriterijų“ (Vitgenšteinas 1995: §580). Vienokia ar kitokia žmogaus samprata (vaizdas) reiškiama „kultūros“ ar "civilizacijos" pobūdžiu, žmoniu gyvenimo būdu: sugebantysis matyti sielos aspektus elgsis kitaip, nei tas, kuris nesugeba. Tai galioja tiek paskiram žmogui, tiek visai kultūrai. Kultūra, kuriai svetima prieiga prie savirodos, t. y. kuri nesupranta religinių vaizdų aspektu, bus kitokia, nei ta, kuri supranta.

Aspekto pokytis pasireiškia kaip elgesio pokytis. Platesniu mastu - tai kultūros pokytis. Paskiro asmens lygiu - tai gyvenimo būdo pokytis. Religijos atveju toks asmeninis aspekto pokytis gali sutapti su religiniu atsivertimu (žr.: Cline 2005). Cline'as parodo, jog ir Augustino atsivertimą pasakojamą „Išpažinimuose", galima suprasti kaip aspekto pokytị: „Matymas kaip“ yra Augustino susitikimas su Dievu" (Cline 2005: 143). Wittgensteino kritines pastabas apie psichologiją galima apibūdinti kaip kelrodi, kreipianti $i$ fundamentalu pokyti ateityje. Tai artima garsiajai Heideggerio pastabai apie būsimajij dievą, kuris vienintelis gali „,išgelbèti“. 


\section{ASPEKTO PASTEBĖJIMAS IR NUOSTABA}

Anot legendos, Ivanas Rūstusis, pamatęs užbaigtą Šv. Vasilijaus soborą Kremliuje (ji Wittgensteinas vertino kaip vietą gražiausiu pastatų), išdūrè architektui akis, kad šis niekad nesukurtu ko nors gražesnio. Kaip pasakoja Drury, Wittgensteinas, išgirdęs ši faktą, reagavo žodžiais: „Koks nuostabus būdas parodyti pasigèrëjimą!" (Wittgenstein, cit. pgl. Bouveresse 2007: 374). Bouveresse'as pakartoja Rheesoas pastabą, jog Wittgensteinas lengvai pripažino, kad toks elgesys siaubingas, atstumiantis, vis dèlto neatsisakydamas savo pirmosios spontaniškos reakcijos - nuostabos (Bouveresse 2007: 374).

Tačiau siekti tokių dalykų paliekamą nuostabos, siaubo ar grèsmingumo ispūdị aiškinti šiu dalykų kilmès moksline hipoteze/interpretacija, anot Wittgensteino, yra klaida. Moksliniu paaiškinimu nusikratoma ritualo paliekamu trikdančiu pirmapradžiu ispūdžiu. Vis dèlto tokie pirmapradžiai isspūdžiai ir mokslingoje visuomenëje gyvenančiam žmogui yra prieinami: „Tarsi žaibas [dabar] būtų banalesnis ar mažiau stulbinantis nei prieš 2000 metü" (Wittgenstein, cit. pgl. Bouveresse 2007: 375). Žaibo saviroda išlieka tokia pati nepaisant pažangiu mokslinių jo atsiradimo aiškinimų. Bet pats polinkio pateikti visa ko mokslini aiškinimą isigalëjimas mus nuskurdina: „Kad stebètųsi, žmogus turi prabusti. Mokslas - tai būdas ji vèl užmigdyti“ (Wittgenstein 1980: 5). Nes tai, kas save rodo, jis pakeičia "aiškinimu“.

Wittgensteino požiūriu "mokslinio aiškinimo" rezultatas dažnai tèra tas, jog gilius dalykus jis redukuoja i „,kažką nepalyginti lèkštesnio“ (Monk 1991: 310). Panašiai, kaip žmogaus sampratos transformacija pagal moderniojo racionalumo standartus redukavo žmogu i jo priešingybę: „O sieliškumo priešingybė yra mašiniškumas“ (Wittgenstein 1984: I §324). Moderniosios mašinos principas yra maksimaliai efektyvus veikimas. Tad matome logini sąryši tarp psichologinio žmogaus vaizdo ir moderniojo gyvenimo būdo, kuriame dominuoja priemoniųtikslų racionalumas. Žodžiu „Seelenvoll“", kuri šiame kontekste minètoje citatoje išvertème žodžiu "sieliškumas“ (sielos turèjimas), Wittgensteinas nurodo gyvenimo gama, kurią eliminuoja scientistine redukcija. Jis nurodo i psichologijos „painiavą ir nykumą" (Vitgenšteinas 1995: §393). Benjafieldas pastebi, jog ankstesnejje teksto versijoje antrojo žodžio - „nykuma“ - nebuvo, tad ,[t]ai skatina manyti, kad Wittgensteinas psichologijos painiavą ir jos nykumą laike šiek tiek skirtingomis problemomis" (Benjafield 2008: 106). Angliškame vertime šis žodis - tai „,barrenness“ (Wittgenstein 1958: 232e), ir ji galime suprasti kaip „bergždumą", t. y. psichologijos netinkamumą vaisingai spręsti tam tikras problemas. Tačiau čia atsižvelkime ir i kitą aspektą. Originale tas žodis - „Öde“" (Wittgenstein 1958: 232), galintis reikšti ir „nuoboduma/nuoboduli“ ar net „erzinantį nuoboduma/nuoboduli". Jame išgirstinas antiscientistinis piktas tonas. Be to, ir nuoroda ì redukuotą - "nuobodų" - dvidešimtojo amžiaus "praktiškai racionalu“", bet „,aklą aspektui“" gyvenimo būdą. 
Wittgensteino ištara, jog jo tikslas filosofijoje yra "parodyti musei kelią iš butelio" (Vitgenšteinas 1995: §309), reiškia, jog jis siekè parodyti būda, kaip išsivaduoti iš savirodą atmetusios mąstymo ir gyvenimo redukcijos. Pasikeitęs požiūris ì nemokslines praktikas turëjo grąžinti ir prideramą santyki su jomis, o kartu kitoki santyki su pasauliu. Wittgensteino mokinys Rhees pažymi, jog sugebejjimas stebėtis (filosofijos pradžia), kurio trūksta Frazeriui ir moderniajai kultūrai, yra būdingas „mažiau sugedusių tautų mąstymui" (Rhees, cit. pgl. Phillips 2003: 195). Jų gyvenimo formos išreiškia nuostabą mirties atžvilgiu (o ne bandymus išvengti mirties ir kuo labiau prailginti gyvenimą), nuostabą (beveik nuolankų pagarbumą) beprotybès atžvilgiu, nuostaba, kad yra tokios problemos, kurios yra, ir kad jos turi sprendimus, kuriuos turi (antikos filosofas savo geometrini atradima, jog bet kuris trikampis, ibrèžtas i pusapskritimi, yra statusis, laikè dievišku apreiškimu), nuostabą dèl gamtovaizdžių grožio, dèl gražių ar siaubingų žmonių charakterių, kurie pasirodo per ju atitinkamus veiksmus, nuostabą dèl vykstančio blogio (o tai nèra stebejjimasis vis dar pasitaikančiomis blogybėmis) ir t. t. (žr.: Phillips 2003: 195). Visų šių moderniajam žmogui tokių nesuprantamų gyvenimo formų prielaida yra pirmapradžių patirčių turejjimas.

Anot biografo Monko galbūt kiek perdèto ir romantizuoto vertinimo, Wittgensteinas netgi buvo linkęs i pesimistinę ir net apokaliptinę žmonijos likimo vizija, kurią lèmè jo pasibaisèjimas tuo, jog dvasią pakeitė mašina, kad buvo nusigręžta nuo Dievo ir pasikliauta mokslu grissta pažanga (žr.: Monk 1991: 489). Modernią̧ą civilizaciją jis apibūdino kaip "pigiai i̇vyniotą i celofaną ir izoliuotą nuo visko, kas didinga, sakytum, nuo Dievo" (Wittgenstein, cit. pgl. Monk 1991: 489).

Didingumas negali būti vien teorizavimo objektas, bet turi būti įkūnytas. Siekiant iš tiesų nubusti iš mokslinio miego, „nieko neduoda vien teisingas mąstymas; reikia veikti - taip sakant, nuplèšti celofaną ir parodyti jo dengiamą gyvajij pasauliı" (Monk 1991: 490). Gyvenimas, anot Wittgensteino, turètų būti pripildytas tokiu prasmių - tokių Sprachspiele, kuriems scientistinè nuostata lieka akla. Wittgensteinas kaip vieną tokio kalbos žaidimo, giminingo religiniams ritualams, pavyzdžių nurodo tai, kaip Schuberto brolis po kompozitoriaus mirties parode jam pagarbą suplèšydamas jo partitūras ir po gabaliuką išdalindamas jo mégstamiausiems mokiniams (žr.: Gooding 2007: 14). Šio veiksmo prasmę ir ivvairių ritualų bei metafizinių siekių gelmę suprantame dèl tų pačių mūsų galių, kurios scientistinèje kultūroje miega. Kaip tikras didingumo apraiškas jis nurodè Mocarto ir Bethoveno gyvenimus ir vadino šiuos kompozitorius „tikrais Dievo sūnumis“ (Wittgenstein, cit. pgl. John 1998: 508). Dianos šventyklos žynio nužudymo ritualas, kurio paaiškinimui savo žymujji veikalą Auksine šakele Frazeris ir paskyrè, Wittgensteinui vertingas atrodè todèl, kad šių žynių gyvenimas taip pat buvo didingumo raiška; šis ritualas buvo puikus simbolis to, ką išreiškia frazè „mirties didingumas" (Bouveresse 2007: 367). Jokia mokslinè hipotezè niekada negalètu pateikti tinkamo šio simbolio supratimo, kaip negali pateikti ir 
tinkamo psichologijos, patirties ar kalbos suvokimo. Juk tai, kaip ir „das Mystische" Loginiame-filosofiniame traktate (anks- tyvojo Wittgensteino nuostaba dèl to, kad pasaulis yra), gali tik „rodyti save“ - kalbos žaidimuose ar gyvenimo formose.

\section{IŠVADA}

Kaip Traktate už paskirus sakinius/ teiginius yra svarbiau pati save rodanti logika, taip ir vèlyvajame Wittgensteino mąstyme už paskiras pastabas ar pateikiamus pavyzdžius yra svarbesnis principas, iš kurio jie kyla ir kuri turètų nurodyti. Šis principas nèra diskursyviai apibrèžiamas, bet tik pagaunamas tiesioginiu - žaibišku - minties judesiu. Witt-

\section{Literatūra}

Bar-Elli G. 2006. Wittgenstein on the Experience of Meaning and the Meaning of Music. Philosophical Investigations 29(3): 217-249.

Benjafield J. G. 2008. Revisiting Wittgenstein on Köhler and Gestalt Psychology. Journal of the History of the Behavioral Sciences 44(2): 99-118.

Bouveresse J. 2007. Wittgenstein's Critique of Frazer. Ratio (New Series) 20(4): 357-376.

Churchill J. 1998. Rat and Mole's Epiphany of Pan: Wittgenstein on Seeing Aspects and Religious Belief. Philosophical Investigations 21(2): 152-172.

Cline E. M. 2005. Augustine's Change of Aspect. Heythrop Journal 46(2): 135-148.

Gooding F. 2007. They Still Believe There's Respect in Dying: Wittgenstein, Tercier, Romero. Critical Quarterly 49(3): 13-30.

John P. C. 1988. Wittgenstein's “Wonderful Life”. Journal of the History of Ideas 49(3): 495-510.

Monk R. 1991. Ludwig Wittgenstein: The Duty of Genius. Vintage, London. gensteino filosofija nèra moralistinè kultūros kritika ar romantizuotas mokslinio-techninio gyvenimo atsisakymas. Veikiau ji laikytina mąstymo pavyzdžiu ir nuoroda ị tokị buvimo būda, kuris yra grịstas mokslinei hipotezei neprieinama Sprachpiele logikos saviroda bei sykiu atvirumu dieviškumui.

Phillips D. Z. 2003. Wittgenstein, Wittgensteinianism, and magic: a philosophical tragedy? Religious Studies 39: 185-201.

Stasiulis N. 2017. Sprachspiel ir ritualas L. Wittgensteino filosofijoje. Logos 93: 78-84.

Vitgenšteinas L. 1995. Filosofiniai tyrinëjimai. Rinktiniai raštai. Mintis, Vilnius.

Wittgenstein L. 1958. Philosophische Untersuchungen/ Philosophical Investigations. (Zweite Auflage/Second Edition). Blackwell Publishing: Oxford.

Wittgenstein L. 1980. Vermischte Bemerkungen/Culture and Value. The University of Chicago Press: Chicago.

Wittgenstein L. 1984. Bemerkungen über die Philosophie der Psychologie. Werkausgabe. Suhrkamp: Frankfurt Am Main.

Wittgenstein L. 1984a. Letzte Schriften über die Philosophie der Psychologie. Werkausgabe. Suhrkamp: Frankfurt Am Main. 